\title{
Regulation of APC/C-Cdh1 and Its Function in Neuronal Survival
}

\author{
Angeles Almeida \\ Received: 4 July 2012 / Accepted: 12 July 2012 /Published online: 27 July 2012 \\ (C) The Author(s) 2012. This article is published with open access at Springerlink.com
}

\begin{abstract}
Neurons are post-mitotic cells that undergo an active downregulation of cell cycle-related proteins to survive. The activity of the anaphase-promoting complex/ cyclosome $(\mathrm{APC} / \mathrm{C})$, an E3 ubiquitin ligase that regulates cell cycle progression in proliferating cells, plays a relevant role in post-mitotic neurons. Recent advances in the study of the regulation of $\mathrm{APC} / \mathrm{C}$ have documented that the $\mathrm{APC} / \mathrm{C}-$ activating cofactor, $\mathrm{Cdh} 1$, is essential for the function(s) of $\mathrm{APC} / \mathrm{C}$ in neuronal survival. Here, we review the normal regulation of $\mathrm{APC} / \mathrm{C}$ activity in proliferating cells and neurons. We conclude that in neurons the APC/C-Cdh1 complex actively downregulates the stability of the cell cycle protein cyclin B1 and the glycolytic enzyme 6phosphofructo-2-kinase/fructose-2,6-bisphosphatase-3. Keeping these proteins destabilized is critical both for preventing the aberrant reentry of post-mitotic neurons into the cell cycle and for maintaining their reduced antioxidant status. Further understanding of the pathophysiological regulation of these proteins by APC/C-Cdh1 in neurons will be important for the search for novel therapeutic targets against neurodegeneration.
\end{abstract}

Keywords APC/C $\cdot \mathrm{Cdh} 1 \cdot$ Cell cycle regulation $\cdot$ Neuronal survival $\cdot$ Neurodegeneration

A. Almeida

Instituto de Investigación Biomédica de Salamanca, Hospital

Universitario de Salamanca,

37007 Salamanca, Spain

\section{A. Almeida}

Departamento de Bioquímica y Biología Molecular, Instituto de Neurociencias de Castilla y León, Universidad de Salamanca, 37007 Salamanca, Spain

\footnotetext{
A. Almeida $(\bowtie)$

Research Unit, University Hospital of Salamanca,

Edificio Departamental (Lab. 122), Plaza Doctores de la Reina,

37007 Salamanca, Spain

e-mail: aaparra@usal.es
}

\author{
Abbreviations \\ APC/C Anaphase-promoting complex/cyclosome \\ CNS Central nervous system \\ Cdk Cyclin-dependent kinase \\ D box Destruction box \\ PFKFB3 6-Phosphofructo-2-kinase/fructose-2,6-bisphos- \\ phatase-3 \\ NMDA $\quad N$-methyl-D-aspartate \\ PPP Pentose-phosphate pathway \\ RING Really interesting new gene \\ SCF Skp1-Cul1-F-box-protein \\ TGF $\beta \quad$ Transforming growth factor $\beta$ \\ TPR Tetratricopeptide \\ UPS Ubiquitin proteasome system \\ ZBR Zinc-binding region
}

\section{Introduction}

The cell cycle is an essential process for the development, differentiation, and proliferation of eukaryotic cells. Classically, the cell cycle is divided into four phases, namely, G1, S, G2, and M. Proper progression from one phase to the other is monitored by checkpoints that sense possible defects during DNA synthesis and chromosome segregation [1]. Progression through the cell cycle is controlled by the appropriate and timely activation of cell cycle proteins. This control is executed by the ubiquitin proteasome system (UPS). The UPS consists of sets of enzymes that target substrates to proteasomal destruction by covalently attaching a polyubiquitin chain in an enzymatic cascade [2]. First, ubiquitin is covalently linked to the E1 ubiquitin-activating enzyme in an energy (ATP)-dependent manner. Ubiquitin is then transferred to the E2 ubiquitin-conjugating enzyme. Finally, the E3 ubiquitin ligase recruits both the E2 ubiquitin-conjugating enzyme and substrate, thus 
facilitating the transfer of ubiquitin to the lysine residues of the substrate. Polyubiquitinated substrates are then recognized by the proteasome, which leads them to degradation [2].

The specificity of the UPS is conferred by a large and varied collection of E3 ubiquitin ligases. The cullinreally interesting new gene (RING)-finger-type E3s constitute one of the largest classes of E3s and are essential for the maintenance of genomic integrity and cellular homeostasis [3]. Two major cullin-RING-E3 ubiquitin ligases, the SKP1-CUL1-F-box-protein (SCF) complex and the anaphase-promoting complex, also called the cyclosome $(\mathrm{APC} / \mathrm{C})$, are responsible for targeting cell cycle proteins for degradation. Whereas SCF ubiquitylates substrates from late $\mathrm{Gl}$ to early $\mathrm{M}$ phase, the $\mathrm{APC} / \mathrm{C}$ is active from the onset of mitosis to the end of the G1 phase of the cell cycle [4,5]. Differentiated cells, such as neurons, remain resting in the G0 phase due to an active downregulation of cell cycle-related proteins. However, recent evidence has indicated that neurons retain the ability to reactivate the cell cycle in response to central nervous system (CNS) insults. Thus, neurons attempt to reenter the cell cycle under pathological circumstances, including both acute injury and chronic neurodegenerative disorders [6-8]. For instance, in vivo evidence has revealed $\mathrm{S}$ phase entry in ischemic neurons [9] and aberrant expression of mitotic cyclin B1 in degenerating neurons in Alzheimer's disease [10]. Thus, dysregulation of the cell cycle machinery might be a pathway common to several neurodegenerative disorders and other CNS diseases [11]. It has recently been reported that $\mathrm{APC} / \mathrm{C}$ activity, which regulates cell cycle progression in proliferating cells [12-14], is also essential for neuronal survival $[15,16]$, linking proliferation to neurodegeneration. This review summarizes recent findings describing the functions of $\mathrm{APC} / \mathrm{C}$ in neuronal cell death.

\section{The APC/C Complex}

The APC/C is a multi-subunit cullin-RING E3 ubiquitin ligase assembled from 13 different core subunits that regulates progression from metaphase to anaphase and exit from mitosis [12-14, 17]. Among these subunits, the bestcharacterized ones are the cullin and RING proteins Apc2 and Apc11, which are responsible for catalytic activity, the tetratricopeptide (TPR) repeat subunit Apc3 (or Cdc27), which interacts with co-activators, and the Apc10, also known as Doc1 [17, 18]. The RING-finger protein Apc11 interacts directly with the Ub-conjugated E2 enzyme, while the cullin domain of Apc2 interacts with the RING-finger domain of Apc11, acting as a scaffold to connect Apc11 to the enzyme [19].

\section{Regulation of the $\mathrm{APC} / \mathrm{C}$ in the Cell Cycle}

The activity of the APC/C is tightly regulated along the cell cycle. This is exerted through a combination of co-activator subunits, reversible phosphorylation, and inhibitory proteins and complexes [12-14]. To be active, the APC/C requires the binding of either one of two WD40-domain co-activator proteins, $\mathrm{Cdc} 20$ or Cdh1, which also participate in substrate recognition [20-22]. The activators interact dynamically with the TPR domains in Apc3 and may either facilitate recruitment of substrates through their WD40 domains or enhance the specific activity of the APC/C [23]. The TPR subunit Apc3 also interacts with the Apc10 subunit [24]. Apc10 contains a $\beta$-barrel structure, known as the Doc domain that is involved in substrate binding and recognition $[25,26]$.

Activation of the APC/C by $\mathrm{Cdc} 20$ or $\mathrm{Cdh} 1$ is regulated tightly and oppositely by phosphorylation events. In early mitosis, cyclin-cyclin-dependent kinase (Cdk) complexes phosphorylate some APC/C subunits, hence promoting the binding of $\mathrm{Cdc} 20$ to the complex [27]. APC/C-Cdc20 thus initiates a sequence of degradation of mitotic cyclins that results in decreased Cdk activity, leading to the initiation of anaphase. In contrast, the phosphorylation of Cdh1 by Cdks during $\mathrm{S}$ phase, $\mathrm{G} 2$, and mitosis inhibits its binding to the $\mathrm{APC} / \mathrm{C}[28,29]$. During exit from mitosis, the inactivation of Cdks and subsequent activation of phosphatases [30] allows $\mathrm{Cdh} 1$ dephosphorylation, leading to the activation of the APC/C-Cdh1 complex. In turn, APC/C-Cdh1 ubiquitylates $\mathrm{Cdc} 20$, thus preventing the simultaneous activation of both APC/C co-activators. APC/C-Cdh1 also targets A/B types of mitotic cyclins for destruction, completing the inactivation of Cdk1. In particular, cyclin B1 is degraded in two phases, sequentially regulated by APC/C-Cdc20 and APC/C-Cdh1 [31, 32]. Subsequently, during early mitosis, $\mathrm{Cdc} 20$ activates $\mathrm{APC} / \mathrm{C}$, whereas in late mitosis $\mathrm{APC} / \mathrm{C}-$ Cdh1 activation controls mitotic exit and G1 maintenance, thus regulating the onset of DNA replication [12-14].

\section{Substrate Recognition by APC/C-Cdh1}

$\mathrm{APC} / \mathrm{C}-\mathrm{Cdc} 20$ and APC/C-Cdh1 have different substrate specificities, which allow the orchestration of cell cycle protein degradation in the correct order. Selection of the $\mathrm{APC} / \mathrm{C}$ targets is controlled by the recognition of short degron motifs, predominantly the destruction (D) box (RxxLxxxxN) and the KEN box (KENxxxN) [17]. The D box was first described to be necessary and sufficient for the 
APC/C-mediated ubiquitylation of B type cyclins [33-35]. The KEN motif is commonly present in $\mathrm{APC} / \mathrm{C}$ substrates, usually in addition to the D box [36]; however, some substrates contain only either a D box or KEN box, in one or more copies each. While the D box is recognized by both $\mathrm{APC} / \mathrm{C}-\mathrm{Cdc} 20$ and APC/C-Cdh1, the latter also recognizes targets with a KEN box motif [33, 36, 37]. Although the presence of $\mathrm{D}$ and KEN box sequences in proteins is required for APC/C-mediated ubiquitination of many substrates, it is often not sufficient. Other less known motifs, such as the A box (RxLxPSN), the CRY (CRYxPS) box, and the KEN-like GxEN box, have also been identified [38]. For instance, Aurora A contains both a D box and a KEN box, but its recognition by APC/C-Cdh1 also requires the destruction motif A box [39]. Furthermore, the APC/CCdh1-dependent destruction of $\mathrm{Cdc} 20$ requires not only its KEN box but also its CRY box [40]. Finally, Castro et al. [41] identified a GxEN box within the C-terminus of XKid, a protein involved in chromosome segregation in anaphase; this GxEN box being necessary for its recognition and association with APC/C.

Yamano et al. [42] described a direct interaction of the $\mathrm{APC} / \mathrm{C}$ core with substrates via the degron motifs. The core subunit Doc1/Apc10 appears to regulate the direct interaction and binding of specific substrates [43, 44]. Site-directed mutagenesis analyses in Apc10/Doc1 demonstrated that this subunit specifically mediates D box-dependent recognition [25]; however, Apc10/Doc1 does not participate in the recognition of KEN box by Cdh1. Recently, da Fonseca et al. [26] have reported that Cdh1 and Doc1/Apc10 function as the $\mathrm{D}$ box co-receptor.

\section{Phosphorylation of Cdh1 and APC/C Activity}

The activity of APC/C-Cdh1 increases in late anaphase and is maintained elevated through the G1 phase of the cell cycle, and it is tightly regulated through the reversible phosphorylation of Cdh1 and its substrates, inhibitor proteins, and Cdh1 degradation (Fig. 1). The phosphorylation of Cdh 1 by Cdk1 and Cdk2, which starts from G1/S transition to anaphase, blocks its own interaction and binding to APC/C [28]. Recently, it has been described that Cdk5, a member of the CNS predominant Cdk family that is essential for synaptic plasticity [45] and neurotoxicity [46, 47], phosphorylates (and inactivates) Cdh1 [16].

It is known that Cdh1 dephosphorylation depends not only on Cdk inactivation but also on phosphatase activation [30]. In budding yeast, the main Cdh1 phosphatase, Cdc14, mediates the activation of both $\mathrm{Cdh} 1$ and the $\mathrm{Cdk} 1$ inhibitor protein Sic1, leading to the completion of Cdk1 inactivation $[48,49]$. However, although three homologues of yeast Cdc14 (CDC14A, CDC14B, and CDC14C) have been

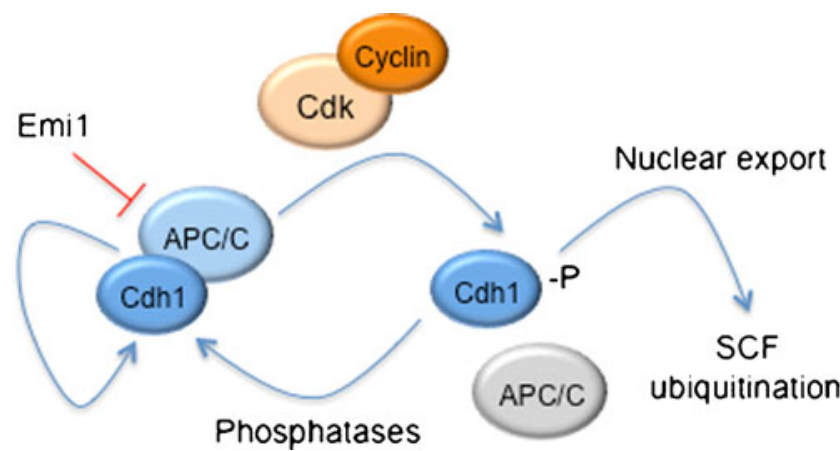

Fig. 1 Regulation of APC/C-Cdh1 activity. The activity of APC/CCdh1 is tightly regulated by reversible phosphorylation of Cdh1, inhibitor proteins, and Cdh1 degradation. The phosphorylation of Cdh1 by cyclin-Cdks blocks its own interaction and binding to APC/ C. Cdh1 dephosphorylation triggers APC/C-Cdh1 activation. Phosphorylated Cdh1 is translocated from the nuclei to the cytosol where it is recognized and targeted for degradation by the SCF complex. Cdh1 is also inhibited by Emil, which acts as a pseudosubstrate that inactivates $\mathrm{APC} / \mathrm{C}-\mathrm{Cdh} 1$ at $\mathrm{G} 2$ and $\mathrm{G} 1 / \mathrm{S}$ transition. Finally, Cdh1 mediates its own degradation by stimulating APC/C activity, which depends upon two D boxes

identified in vertebrates, their relevance remains unclear, given the lack of a clear effect on mitotic exit [50-53]. By contrast, mitotic exit in animal cells is independent of Cdc14 and, instead, relies on phosphatases of the PP1 and PP2A families [30]. In this context, numerous studies suggest functions of vertebrate $\mathrm{Cdc1} 14$ that are unrelated to mitotic exit, including roles in the DNA damage checkpoint [54], DNA repair [53], and centrosome duplication and function $[51,55]$. In particular, in response to genotoxic stress in G2, Cdc14B translocates from the nucleolus to the nucleoplasm, where this phosphatase dephosphorylates $\mathrm{Cdh} 1$, hence promoting APC/C-Cdh1 activity [54].

The phosphorylation of Cdh1 substrates also contributes to the regulation of APC/C-Cdh1 activity. For example, Cdk2-mediated phosphorylation of the SCF E3 ubiquitin ligase cofactor, Skp2, disrupts its association with APC/CCdh1, leading to Skp2 accumulation at the end of G1 phase $[56,57]$. On the other hand, Cdc14B-dependent dephosphorylation of Cdh1 promotes Skp2 degradation at the M/ G1 transition [58].

In addition to inhibitory phosphorylation by Cdks, Cdh1 is also inhibited by Emil, which acts as a pseudosubstrate that inactivates APC/C-Cdh1 at G2 and the G1/S transition [59-61]. Emil contains a D box motif that mediates its own binding to $\mathrm{APC} / \mathrm{C}-\mathrm{Cdh} 1$, thus blocking the accessibility of substrates to the enzyme. Moreover, Emil also contains a ZBR motif that directly inhibits APC/C E3 ligase activity [62].

The subcellular localization of Cdh1 provides an important element of spatial regulation of APC/C-Cdh1 activity $[63,64]$. Cdh1 is located in the nuclei during G1 but redistributes to the cytosol between $\mathrm{S}$ phase and the end of 
mitosis [63]. Nuclear export of Cdh1 to the cytosol is promoted by Cdk phosphorylation [16, 63], which sequesters $\mathrm{Cdh} 1$ from either the APC/C or nuclear targets, thus contributing to the efficient inactivation of APC/C-Cdh1. Furthermore, phosphorylated $\mathrm{Cdh} 1$ is recognized and targeted for degradation by the SCF complex, the predominant E3 ubiquitin ligase in S phase [65].

Finally, Listovsky et al. [66] have described that $\mathrm{APC} / \mathrm{C}$ activity is regulated by $\mathrm{Cdh} 1$ protein abundance. The levels of Cdh1 are high in mitosis, when it is inactive; however, when Cdh1 is active in G1 and G0, its levels are considerably lower, although mostly associated with $\mathrm{APC} / \mathrm{C}$. Those authors concluded that $\mathrm{Cdh} 1$ mediates its own degradation by stimulating APC/C activity, which depends upon two $\mathrm{D}$ boxes [66]. In addition, Rape and Kirschner [67] reported that APC/ C-Cdh1-mediated proteasomal degradation of the ubiquitin-conjugating enzyme (E2) UbcH10 also provides a negative feedback mechanism that inactivates APC/C-Cdh1 during the G1/S transition.

\section{APC/C-Cdh1 in G0/G1 Regulation}

As mentioned above, cyclin-Cdk complexes phosphorylate Cdh1, inhibiting its binding to the APC/C complex [28, 29]; the concomitant inhibition of $\mathrm{APC} / \mathrm{C}$ activity is released when cyclin-Cdk activity decreases and Cdh1 phosphorylation stops in late mitosis. This leads to APC/C-Cdh1 reactivation, which in turn maintains the cyclin $\mathrm{B}-\mathrm{Cdk} 1$ inactive during late mitosis [68]. In this phase, APC/C-Cdh1 also mediates the degradation of regulators of cytokinesis and centrosome replication, such as Aurora A, Aurora B, Plk1, Anillin, and Tpx2, among other proteins [69, 70].

During G1, APC/C-Cdh1 remains active by maintaining the activity of cyclin-Cdk complexes low. In this context, active APC/C-Cdh1 targets A/B types of mitotic cyclins for proteasomal degradation [71, 72]. Moreover, APC/C-Cdh1 can also inactivate Cdk activity by promoting the degradation of the Cdk activator, Cdc25A, and the two cofactors of the SCF E3 ubiquitin ligase: Skp2 and Cks1. This leads to the accumulation of Cdk inhibitors p21, p27, and p57 [56, 57]. APC/C-Cdh1 also limits the expression of cyclin D1 through the elimination of the transcription factor Ets2 [73]. Thus, depletion of Cdh1 by siRNA has been shown to stabilize Skp2 and Ets2, resulting in p21 and p27 degradation and cyclin D1 elevation in G1, followed by a shorter G1 phase and premature entry into S phase [56, 73, 74]. Moreover, in Cdh1-deficient cells, the shortening of the G1 phase is associated with a prolonged and defective $\mathrm{S}$ phase [74-76]. As will be discussed below, in post-mitotic neurons, Cdh1 depletion causes a reentry into the $\mathrm{S}$ phase of the cell cycle followed by apoptotic cell death [15].
During G1, most cells commit alternatively to DNA replication and division or to cell cycle exit and differentiation. Because of its crucial role in $\mathrm{G} 1 / \mathrm{G} 0$ regulation and maintenance of quiescence, APC/C-Cdh1 has been proposed to be responsible for linking cell cycle exit and differentiation in certain cell types [14, 38] (Fig. 2). BarOn et al. [77] have recently described that APC/C-Cdh1mediated Skp2 degradation, and the subsequent p27 accumulation are essential for human embryonic stem cell differentiation.

APC/C-Cdh1 is also crucial for the coordination of cell cycle progression and the initiation of lens [78] and muscle cell [79] differentiation. APC/C-Cdh1-regulated lens differentiation is mediated by transforming growth factor (TGF) $\beta$-induced destruction of SnoN, a transcriptional repressor of the Cdk inhibitors p15 and p21 (Fig. 2). Thus, depletion of Cdh 1 by RNA interference attenuates the TGF $\beta$-mediated induction of $\mathrm{p} 15$ and $\mathrm{p} 21$ and blocks lens differentiation [78]. Furthermore, TGF $\beta$ induces Skp2 degradation mediated by the Smad cascade, which stabilizes p27 and p21 and thereby contributes to TGF $\beta$-induced cell cycle arrest [80]. In muscle, APC/C-Cdh1 regulates two critical proteins, Skp2 and Myf5, for proteolysis during muscle differentiation [79]. On the one hand, the targeting of Skp2 by APC/C-Cdh1 for destruction results in an accumulation of $\mathrm{p} 21$ and $\mathrm{p} 27$, which are crucial for coordinating cellular division and differentiation. On the other hand, the degradation of Myf5 facilitates myogenic fusion.

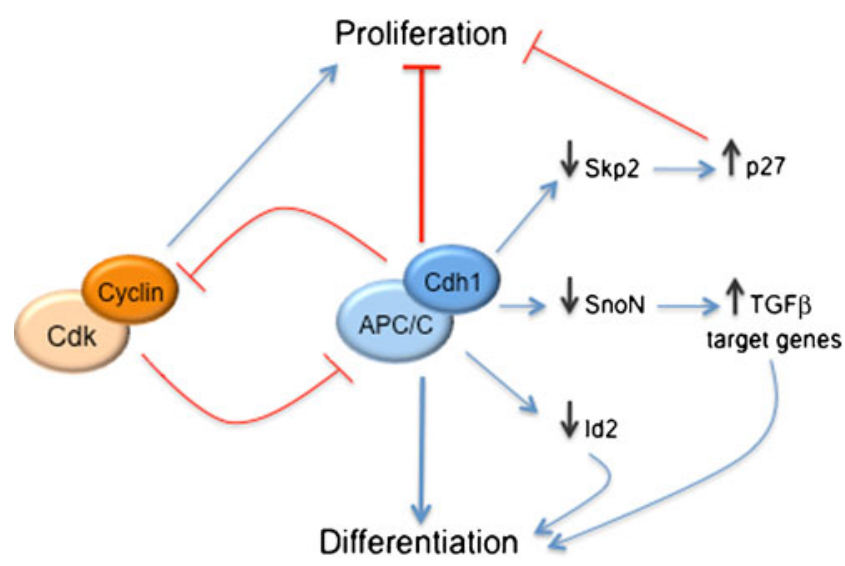

Fig. $2 \mathrm{APC} / \mathrm{C}-\mathrm{Cdh} 1$ coordinates cell cycle arrest and cellular differentiation. APC/C-Cdh1 inhibits cell proliferation by promoting the degradation of Cdk activators, such as cyclins, and the stabilization of Cdk inhibitors, including p27. APC/C-Cdh1 targets Skp2 for proteasomal degradation, leading to p27 accumulation and cell cycle arrest. Cyclin-Cdk complex phosphorylates Cdh1 and prevents APC/ $\mathrm{C}$ activation. TGF $\beta$ stimulates APC/C-Cdh1-mediated SnoN degradation, leading to activation of TGF $\beta$ target genes and growth inhibition. APC/C-Cdh1 also triggers Id2 (inhibitor of differentiation/DNA binding 2) degradation. This promotes the activation of basic helix-loophelix transcription factors and targets gene expression that mediates cellular differentiation 


\section{APC/C-Cdh1 in Neuronal Differentiation}

The activation of APC/C-Cdh1 is also required for neuronal differentiation. It has been reported that $\mathrm{APC} / \mathrm{C}-\mathrm{Cdh} 1$ mediates retinoic acid-induced neuronal differentiation from $\mathrm{SH}-$ SY5Y neuroblastoma cells [74]. Thus, retinoic acid induces the nuclear accumulation of Cdh1 that parallels Skp2 destabilization and p27 accumulation. Furthermore, retinoic acid decreases the mRNA and protein levels of Rae $1-$ a nuclear export factor that limits APC/C-Cdh1 activity in mitosishence facilitating APC/C-Cdh1-mediated Skp2 degradation, leading to cell cycle arrest and neuroblastoma differentiation [74]. The regulation of this Skp2-p27 axis by APC/C-Cdh1 has also been found to be involved in the terminal differentiation of neuronal precursors in response to nerve growth factor [81].

Finally, APC/C-Cdh1 regulates axonal growth and patterning through the degradation of two nuclear proteins, namely, the inhibitor of differentiation/DNA binding 2 (Id2) and SnoN [82, 83] (Fig. 2). In the developing nervous system, Id 2 enhances cell proliferation, promotes tumor progression, and inhibits the activity of neurogenic basic helix-loop-helix transcription factors [84]. Lasorella et al. [82] demonstrated that APC/C-Cdh1 targets Id2 for degradation through a D box motif that is conserved in Id1 and Id4. Degradation of Id2 in neurons permits the accumulation of the Nogo receptor and the subsequent inhibition of axonal growth. Furthermore, Stegmuller et al. [83] found that the Cdh1-dependent inhibition of TGF $\beta$-SnoN axis stimulates axonal growth.

\section{Cyclin B1 Stability Regulation by APC/C-Cdh1 in Neuronal Survival}

Several core subunits of $\mathrm{APC} / \mathrm{C}$ and $\mathrm{Cdh} 1$ are highly expressed in mammalian brain post-mitotic neurons [15, 85]. In neurons, depletion of Cdh1 by RNA interference rapidly triggers apoptotic neuronal death. Thus, APC/C$\mathrm{Cdh} 1$ is required to maintain low levels of cyclin $\mathrm{B} 1$ in order to prevent an aberrant entry into the cell cycle that will lead to neuronal apoptosis (Fig. 3). Cdh1 then regulates neuronal survival [15]. Under physiological conditions, glutamate receptor-mediated excitatory neurotransmission plays a central role in neural development, differentiation, and synaptic plasticity. However, excessive or prolonged activation of glutamate receptors induces neurotoxicity, a process that has been defined as excitotoxicity [86, 87]. Excitotoxicity mediates neuronal death in several neurological disorders, including stroke and chronic neurodegenerative diseases $[87,88]$. In a previous study, the changes in cyclin B1 protein levels following an excitotoxic stimulus caused by a short (5 $\mathrm{min}$ ) incubation of post-mitotic cortical

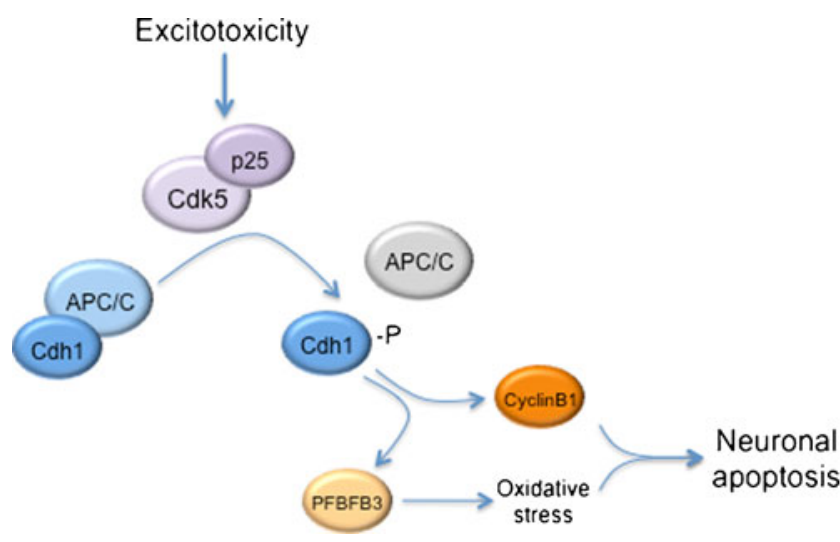

Fig. $3 \mathrm{APC} / \mathrm{C}-\mathrm{Cdh} 1$ regulates neuronal apoptosis. Excitotoxicityinduced Cdk5-p25 activation phosphorylates Cdh1. APC/C-Cdh1 inactivation causes the stabilization of the cell cycle protein cyclin B1 and the glycolytic enzyme 6-phosphofructo-2-kinase/fructose-2,6bisphosphatase-3 (PFKFB3). Stabilization of these proteins induces both aberrant reentry of post-mitotic neurons into the cell cycle and oxidative stress, leading to neuronal apoptosis

neurons with glutamate $(100 \mu \mathrm{M})$ or the specific glutamate receptor subtype agonist, $N$-methyl-D-aspartate (NMDA; $100 \mu \mathrm{M})$ were investigated. Under these conditions, neurons died in an NMDA receptor-dependent manner [89]. Western blot analyses of neurons revealed that both glutamate and NMDA promoted an accumulation of cyclin B1 in the neuronal nuclei that was fully prevented by silencing cyclin B1 [16]. Furthermore, cyclin B1 nuclear accumulation was responsible for a large proportion of the apoptotic death caused by glutamate and NMDA. It was also found that glutamate and NMDA triggered Cdh1 phosphorylation, sequestering Cdh1 in the cytosol and inhibiting APC-Cdh1 activity.

Using both the Cdk inhibitor roscovitine and an RNA interference strategy, it was also demonstrated that Cdh1 was phosphorylated by Cdk5, an enzyme that can be persistently activated when bound to p25 [46], the proteolytic product of p35 that has previously been shown to accumulate in the neurons of patients with Alzheimer's disease [90]. It was found that Cdk5 small interfering RNA dose-dependently prevented the apoptotic neuronal death triggered by NMDA and glutamate. These data were the first to suggest that NMDA receptor stimulation activates $\mathrm{Cdk} 5$, which phosphorylates Cdh1, leading to cyclin B1 accumulation and neuronal apoptotic death [16]. It is interesting to note that Cdk5 phosphorylates the NMDA receptor NR2A subunit at Ser-1232, hence facilitating NMDA receptor synaptic transmission [91]. Thus, NMDA receptor overactivation, which occurs in prolonged release of the neurotransmitter glutamate such as that occurring in neurodegenerative diseases and stroke [88], could lead to a Cdk5-NMDA receptor activation feedback loop, contributing to the propagation of neurodegeneration. 
Interestingly, cyclin B1 accumulates in degenerating brain areas in Alzheimer's disease [10,92] and stroke [93], which are situations known to be associated with an excitotoxic-type neuronal death [88]. Thus, these data suggest that Cdk5mediated Cdh1 inactivation might contribute to neuronal death in neurological disorders.

\section{APC/C-Cdh1 in Glucose Metabolism and Oxidative Stress: Role in Neurodegeneration}

Neurons are the highest energy-consuming cells of the brain; however, the rate of glycolysis, the metabolic route responsible for the generation of most energy needs in cells, is very low in neurons, particularly in comparison with their neighboring astrocytes [94, 95]. Glucose-derived glucose-6phosphate is the connecting metabolite between glycolysis and the pentose-phosphate pathway (PPP) [96]. The PPP is the main metabolic pathway responsible for the regeneration of $\mathrm{NADPH}\left(\mathrm{H}^{+}\right)$, a required reducing cofactor for many oxidoreductases. Previously, it has been found that in cortical neurons the protein abundance of the glycolytic enzyme 6-phosphofructo-2-kinase/fructose-2,6-bisphosphatase, isoform 3 (PFKFB3) is very low in neurons as compared with that found in astrocytes [95]. This was considered important, since PFKFB3 is a key enzyme controlling the rat of glycolysis, and hence energy generation from glucose. Furthermore, it was found that overexpressing PFKFB3 in neurons increased the rate of glycolysis, although it concomitantly decreased that of the PPP [97].

Interestingly, $\mathrm{PFKFB} 3$ protein was found to be a substrate of APC/C-Cdh1 [97]. Accordingly, APC/C-Cdh1 activity determines the control of the rate of glucose consumption both through glycolysis and the PPP. In contrast to neurons, astrocytes express a very low Cdh1 protein abundance, and hence $\mathrm{APC} / \mathrm{C}$ activity is negligible in these cells [97]. Knocking down Cdh1 in neurons inhibits APC/CCdh1 activity and leads PFKFB3 protein to accumulate, thus shifting glucose consumption towards glycolysis at the expense of a reduction in that of the PPP. Importantly, this causes an impairment in neurons to regenerate NADPH $\left(\mathrm{H}^{+}\right)$, hence promoting oxidative stress by promoting the oxidation of antioxidant glutathione [97].

This tight regulation of glycolysis and PPP by APC/CCdh1 has important consequences for neuronal survival. Thus, when the activation of the rate of glycolysis is prolonged by inhibiting APC/C-Cdh1 activity, neurons undergo apoptotic death [97]; moreover, neuronal death can be fully reversed by incubation with a plasma membrane-permeable form of glutathione [97]. Thus, glucose is preferentially utilized through the PPP to exert antioxidant-mediated neuroprotection, and $\mathrm{APC} / \mathrm{C}-\mathrm{Cdh} 1$ activity is essential to control this physiological function. Future studies will be needed to understand whether Cdh1 deficiency or the inhibition of APC/ $\mathrm{C}$ activity exert any role in the mechanism leading to neurodegeneration.

Acknowledgments This work was supported by FEDER (European Regional Development Fund), Instituto de Salud Carlos III (PS09/0366 and RD06/0026/1008), and Junta de Castilla y León (GREX206).

Open Access This article is distributed under the terms of the Creative Commons Attribution License which permits any use, distribution, and reproduction in any medium, provided the original author(s) and the source are credited.

\section{References}

1. Murray AW (2004) Recycling the cell cycle: cyclins revisited. Cell 116:221-234

2. Hershko A, Ciechanover A (1998) The ubiquitin system. Annu Rev Biochem 67:425-479

3. Lipkowitz S, Weissman AM (2011) RINGs of good and evil: RING finger ubiquitin ligases at the crossroads of tumour suppression and oncogenesis. Nat Rev Cancer 11:629-643

4. Nakayama KI, Nakayama K (2006) Ubiquitin ligases: cell-cycle control and cancer. Nat Rev Cancer 6:369-381

5. Song L, Rape M (2011) Substrate-specific regulation of ubiquitination by the anaphase-promoting complex. Cell Cycle 10:52-56

6. Timsit S, Menn B (2007) Cerebral ischemia, cell cycle elements and Cdk5. Biotechnol J 2:958-966

7. Shakya A, Cooksey R, Cox JE, Wang V, McClain DA, Tantin D (2009) Oct1 loss of function induces a coordinate metabolic shift that opposes tumorigenicity. Nat Cell Biol 11:320-327

8. Hernandez-Ortega K, Quiroz-Baez R, Arias C (2011) Cell cycle reactivation in mature neurons: a link with brain plasticity, neuronal injury and neurodegenerative diseases? Neurosci Bull 27:185196

9. Kuan CY, Schloemer AJ, Lu A, Burns KA, Weng WL, Williams MT, Strauss KI, Vorhees CV, Flavell RA, Davis RJ, Sharp FR, Rakic P (2004) Hypoxia-ischemia induces DNA synthesis without cell proliferation in dying neurons in adult rodent brain. J Neurosci 24:10763-10772

10. Vincent I, Jicha G, Rosado M, Dickson DW (1997) Aberrant expression of mitotic cdc2/cyclin B1 kinase in degenerating neurons of Alzheimer's disease brain. J Neurosci 17:3588-3598

11. Yang Y, Herrup K (2007) Cell division in the CNS: protective response or lethal event in post-mitotic neurons? Biochim Biophys Acta 1772:457-466

12. Peters JM (2006) The anaphase promoting complex/cyclosome: a machine designed to destroy. Nat Rev Mol Cell Biol 7:644-656

13. Thornton BR, Toczyski DP (2006) Precise destruction: an emerging picture of the APC. Genes Dev 20:3069-3078

14. Eguren M, Manchado E, Malumbres M (2011) Non-mitotic functions of the anaphase-promoting complex. Semin Cell Dev Biol 22:572-578

15. Almeida A, Bolanos JP, Moreno S (2005) Cdh1/Hct1-APC is essential for the survival of postmitotic neurons. J Neurosci 25:8115-8121

16. Maestre C, Delgado-Esteban M, Gomez-Sanchez JC, Bolanos JP, Almeida A (2008) Cdk5 phosphorylates Cdh1 and modulates cyclin B1 stability in excitotoxicity. EMBO J 27:2736-2745

17. Barford D (2011) Structural insights into anaphase-promoting complex function and mechanism. Philos Trans R Soc Lond B Biol Sci 366:3605-3624 
18. Matyskiela ME, Rodrigo-Brenni MC, Morgan DO (2009) Mechanisms of ubiquitin transfer by the anaphase-promoting complex. $\mathrm{J}$ Biol 8:92

19. Tang Z, Li B, Bharadwaj R, Zhu H, Ozkan E, Hakala K, Deisenhofer J, Yu H (2001) APC2 Cullin protein and APC11 RING protein comprise the minimal ubiquitin ligase module of the anaphasepromoting complex. Mol Biol Cell 12:3839-3851

20. Schwab M, Lutum AS, Seufert W (1997) Yeast Hct1 is a regulator of Clb2 cyclin proteolysis. Cell 90:683-693

21. Sigrist SJ, Lehner CF (1997) Drosophila fizzy-related downregulates mitotic cyclins and is required for cell proliferation arrest and entry into endocycles. Cell 90:671-681

22. Visintin R, Prinz S, Amon A (1997) CDC20 and CDH1: a family of substrate-specific activators of APC-dependent proteolysis. Science 278:460-463

23. Vodermaier HC, Gieffers C, Maurer-Stroh S, Eisenhaber F, Peters JM (2003) TPR subunits of the anaphase-promoting complex mediate binding to the activator protein $\mathrm{CDH} 1$. Curr Biol 13:1459-1468

24. Wendt KS, Vodermaier HC, Jacob U, Gieffers C, Gmachl M, Peters JM, Huber R, Sondermann P (2001) Crystal structure of the APC10/DOC1 subunit of the human anaphase-promoting complex. Nat Struct Biol 8:784-788

25. Carroll CW, Enquist-Newman M, Morgan DO (2005) The APC subunit Doc1 promotes recognition of the substrate destruction box. Curr Biol 15:11-18

26. da Fonseca PC, Kong EH, Zhang Z, Schreiber A, Williams MA, Morris EP, Barford D (2011) Structures of APC/C(Cdh1) with substrates identify Cdh1 and Apc10 as the D-box co-receptor. Nature 470:274-278

27. Kraft C, Herzog F, Gieffers C, Mechtler K, Hagting A, Pines J, Peters JM (2003) Mitotic regulation of the human anaphasepromoting complex by phosphorylation. EMBO J 22:6598-6609

28. Zachariae W, Schwab M, Nasmyth K, Seufert W (1998) Control of cyclin ubiquitination by CDK-regulated binding of Hct1 to the anaphase promoting complex. Science 282:1721-1724

29. Kramer ER, Scheuringer N, Podtelejnikov AV, Mann M, Peters JM (2000) Mitotic regulation of the APC activator proteins CDC20 and CDH1. Mol Biol Cell 11:1555-1569

30. Wurzenberger C, Gerlich DW (2011) Phosphatases: providing safe passage through mitotic exit. Nat Rev Mol Cell Biol $12: 469-482$

31. Yeong FM, Lim HH, Padmashree CG, Surana U (2000) Exit from mitosis in budding yeast: biphasic inactivation of the Cdc28-Clb2 mitotic kinase and the role of Cdc20. Mol Cell 5:501-511

32. Thornton BR, Toczyski DP (2003) Securin and B-cyclin/CDK are the only essential targets of the APC. Nat Cell Biol 5:1090-1094

33. Glotzer M, Murray AW, Kirschner MW (1991) Cyclin is degraded by the ubiquitin pathway. Nature 349:132-138

34. King RW, Deshaies RJ, Peters JM, Kirschner MW (1996) How proteolysis drives the cell cycle. Science 274:1652-1659

35. Yamano H, Gannon J, Hunt T (1996) The role of proteolysis in cell cycle progression in Schizosaccharomyces pombe. EMBO J 15:5268-5279

36. Pfleger CM, Kirschner MW (2000) The KEN box: an APC recognition signal distinct from the D box targeted by Cdh1. Genes Dev 14:655-665

37. Passmore LA, Barford D (2005) Coactivator functions in a stoichiometric complex with anaphase-promoting complex/cyclosome to mediate substrate recognition. EMBO Rep 6:873-878

38. Wasch R, Robbins JA, Cross FR (2010) The emerging role of $\mathrm{APC} / \mathrm{CCdh} 1$ in controlling differentiation, genomic stability and tumor suppression. Oncogene 29:1-10

39. Littlepage LE, Ruderman JV (2002) Identification of a new APC/C recognition domain, the A box, which is required for the Cdh1dependent destruction of the kinase Aurora-A during mitotic exit. Genes Dev 16:2274-2285
40. Reis A, Levasseur M, Chang HY, Elliott DJ, Jones KT (2006) The CRY box: a second APCcdh1-dependent degron in mammalian cdc20. EMBO Rep 7:1040-1045

41. Castro A, Vigneron S, Bernis C, Labbe JC, Lorca T (2003) Xkid is degraded in a D-box, KEN-box, and A-box-independent pathway. Mol Cell Biol 23:4126-4138

42. Yamano H, Gannon J, Mahbubani H, Hunt T (2004) Cell cycleregulated recognition of the destruction box of cyclin $\mathrm{B}$ by the APC/C in Xenopus egg extracts. Mol Cell 13:137-147

43. Carroll CW, Morgan DO (2002) The Doc1 subunit is a processivity factor for the anaphase-promoting complex. Nat Cell Biol 4:880-887

44. Passmore LA, McCormack EA, Au SW, Paul A, Willison KR, Harper JW, Barford D (2003) Doc1 mediates the activity of the anaphase-promoting complex by contributing to substrate recognition. EMBO J 22:786-796

45. Hawasli AH, Benavides DR, Nguyen C, Kansy JW, Hayashi K, Chambon P, Greengard P, Powell CM, Cooper DC, Bibb JA (2007) Cyclin-dependent kinase 5 governs learning and synaptic plasticity via control of NMDAR degradation. Nat Neurosci 10:880-886

46. Lee MS, Kwon YT, Li M, Peng J, Friedlander RM, Tsai LH (2000) Neurotoxicity induces cleavage of p35 to p25 by calpain. Nature 405:360-364

47. Hamdane M, Buee L (2007) The complex p25/Cdk5 kinase in neurofibrillary degeneration and neuronal death: the missing link to cell cycle. Biotechnol J 2:967-977

48. Jaspersen SL, Charles JF, Morgan DO (1999) Inhibitory phosphorylation of the APC regulator Hct1 is controlled by the kinase Cdc28 and the phosphatase Cdc14. Curr Biol 9:227-236

49. Stegmeier F, Amon A (2004) Closing mitosis: the functions of the Cdc14 phosphatase and its regulation. Annu Rev Genet 38:203232

50. Saito RM, Perreault A, Peach B, Satterlee JS, van den Heuvel S (2004) The CDC-14 phosphatase controls developmental cellcycle arrest in C. elegans. Nat Cell Biol 6:777-783

51. Kaiser BK, Zimmerman ZA, Charbonneau H, Jackson PK (2002) Disruption of centrosome structure, chromosome segregation, and cytokinesis by misexpression of human Cdc14A phosphatase. Mol Biol Cell 13:2289-2300

52. Berdougo E, Nachury MV, Jackson PK, Jallepalli PV (2008) The nucleolar phosphatase $\mathrm{Cdc14 \textrm {B }}$ is dispensable for chromosome segregation and mitotic exit in human cells. Cell Cycle 7:11841190

53. Mocciaro A, Berdougo E, Zeng K, Black E, Vagnarelli P, Earnshaw W, Gillespie D, Jallepalli P, Schiebel E (2010) Vertebrate cells genetically deficient for Cdc14A or Cdc14B retain DNA damage checkpoint proficiency but are impaired in DNA repair. J Cell Biol 189:631-639

54. Bassermann F, Frescas D, Guardavaccaro D, Busino L, Peschiaroli A, Pagano M (2008) The Cdc14B-Cdh1-Plk1 axis controls the G2 DNA-damage-response checkpoint. Cell 134:256-267

55. Mailand N, Lukas C, Kaiser BK, Jackson PK, Bartek J, Lukas J (2002) Deregulated human Cdc14A phosphatase disrupts centrosome separation and chromosome segregation. Nat Cell Biol 4:317-322

56. Wei W, Ayad NG, Wan Y, Zhang GJ, Kirschner MW, Kaelin WG (2004) Degradation of the SCF component Skp2 in cell-cycle phase G1 by the anaphase-promoting complex. Nature 428:194198

57. Bashir T, Dorrello NV, Amador V, Guardavaccaro D, Pagano M (2004) Control of the SCF(Skp2-Cks1) ubiquitin ligase by the APC/C(Cdh1) ubiquitin ligase. Nature 428:190-193

58. Rodier G, Coulombe P, Tanguay PL, Boutonnet C, Meloche S (2008) Phosphorylation of Skp2 regulated by CDK2 and Cdc14B protects it from degradation by APC(Cdh1) in G1 phase. EMBO J 27:679-691 
59. Grosskortenhaus R, Sprenger F (2002) Rca1 inhibits APC-Cdh1 (Fzr) and is required to prevent cyclin degradation in G2. Dev Cell 2:29-40

60. Hsu JY, Reimann JDR, Sørensen CS, Lukas J, Jackson PK (2002) EF2-dependent accumulation of hEmil regulates $\mathrm{S}$ phase entry by inhibiting APC-Cdh1. Nat Cell Biol 4:358-366

61. Di Fiore B, Pines J (2008) Defining the role of Emi1 in the DNA replication-segregation cycle. Chromosoma 117:333-338

62. Miller JJ, Summers MK, Hansen DV, Nachury MV, Lehman NL, Loktev A, Jackson PK (2006) Emil stably binds and inhibits the anaphase-promoting complex/cyclosome as a pseudosubstrate inhibitor. Genes Dev 20:2410-2420

63. Jaquenoud M, van Drogen F, Peter M (2002) Cell cycle-dependent nuclear export of Cdh1p may contribute to the inactivation of APC/C(Cdh1). EMBO J 21:6515-6526

64. Zhou Y, Ching YP, Ng RW, Jin DY (2003) Differential expression, localization and activity of two alternatively spliced isoforms of human APC regulator CDH1. Biochem J 374:349-358

65. Benmaamar R, Pagano M (2005) Involvement of the SCF complex in the control of Cdh1 degradation in S-phase. Cell Cycle 4:1230 1232

66. Listovsky T, Oren YS, Yudkovsky Y, Mahbubani HM, Weiss AM, Lebendiker M, Brandeis M (2004) Mammalian Cdh1/Fzr mediates its own degradation. EMBO J 23:1619-1626

67. Rape M, Kirschner MW (2004) Autonomous regulation of the anaphase-promoting complex couples mitosis to S-phase entry. Nature 432:588-595

68. Qiao X, Zhang L, Gamper AM, Fujita T, Wan Y (2010) APC/CCdh1: from cell cycle to cellular differentiation and genomic integrity. Cell Cycle 9:3904-3912

69. Stewart S, Fang G (2005) Anaphase-promoting complex/cyclosome controls the stability of TPX2 during mitotic exit. Mol Cell Biol 25:10516-10527

70. Zhao WM, Fang G (2005) Anillin is a substrate of anaphasepromoting complex/cyclosome (APC/C) that controls spatial contractility of myosin during late cytokinesis. J Biol Chem 280:33516-33524

71. Brandeis M, Hunt T (1996) The proteolysis of mitotic cyclins in mammalian cells persists from the end of mitosis until the onset of S phase. EMBO J 15:5280-5289

72. Wasch R, Cross FR (2002) APC-dependent proteolysis of the mitotic cyclin $\mathrm{Clb} 2$ is essential for mitotic exit. Nature 418:556562

73. Li M, Shin YH, Hou L, Huang X, Wei Z, Klann E, Zhang P (2008) The adaptor protein of the anaphase promoting complex Cdh1 is essential in maintaining replicative lifespan and in learning and memory. Nat Cell Biol 10:1083-1089

74. Cuende J, Moreno S, Bolanos JP, Almeida A (2008) Retinoic acid downregulates Rae1 leading to APC(Cdh1) activation and neuroblastoma SH-SY5Y differentiation. Oncogene 27:3339-3344

75. Garcia-Higuera I, Manchado E, Dubus P, Canamero M, Mendez J, Moreno S, Malumbres M (2008) Genomic stability and tumour suppression by the APC/C cofactor Cdh1. Nat Cell Biol 10:802811

76. Sigl R, Wandke C, Rauch V, Kirk J, Hunt T, Geley S (2009) Loss of the mammalian APC/C activator FZR1 shortens G1 and lengthens $\mathrm{S}$ phase but has little effect on exit from mitosis. J Cell Sci 122:4208-4217

77. Bar-On O, Shapira M, Skorecki K, Hershko A, Hershko DD (2010) Regulation of APC/C (Cdh1) ubiquitin ligase in differentiation of human embryonic stem cells. Cell Cycle 9:1986-1989
78. Wu G, Glickstein S, Liu W, Fujita T, Li W, Yang Q, Duvoisin R, Wan Y (2007) The anaphase-promoting complex coordinates initiation of lens differentiation. Mol Biol Cell 18:1018-1029

79. Li W, Wu G, Wan Y (2007) The dual effects of Cdh1/APC in myogenesis. FASEB J 21:3606-3617

80. Liu W, Wu G, Li W, Lobur D, Wan Y (2007) Cdh1-anaphasepromoting complex targets Skp2 for destruction in transforming growth factor beta-induced growth inhibition. Mol Cell Biol 27:2967-2979

81. Harmey D, Smith A, Simanski S, Moussa CZ, Ayad NG (2009) The anaphase promoting complex induces substrate degradation during neuronal differentiation. J Biol Chem 284:4317-4323

82. Lasorella A, Stegmuller J, Guardavaccaro D, Liu G, Carro MS, Rothschild G, de la Torre-Ubieta L, Pagano M, Bonni A, Iavarone A (2006) Degradation of Id2 by the anaphase-promoting complex couples cell cycle exit and axonal growth. Nature 442:471-474

83. Stegmuller J, Huynh MA, Yuan Z, Konishi Y, Bonni A (2008) TGF $\beta$-Smad2 signaling regulates the Cdh1-APC/SnoN pathway of axonal morphogenesis. J Neurosci 28:1961-1969

84. Perk J, Iavarone A, Benezra R (2005) Id family of helix-loop-helix proteins in cancer. Nat Rev Cancer 5:603-614

85. Gieffers C, Peters BH, Kramer ER, Dotti CG, Peters JM (1999) Expression of the $\mathrm{CDH} 1$-associated form of the anaphasepromoting complex in postmitotic neurons. Proc Natl Acad Sci USA 96:11317-11322

86. Olney JW (1969) Brain lesions, obesity, and other disturbances in mice treated with monosodium glutamate. Science 164:719-721

87. Wang Y, Qin ZH (2010) Molecular and cellular mechanisms of excitotoxic neuronal death. Apoptosis 15:1382-1402

88. Bossy-Wetzel E, Schwarzenbacher R, Lipton SA (2004) Molecular pathways to neurodegeneration. Nat Med 10:S2-S9

89. Almeida A, Bolaños JP (2001) A transient inhibition of mitochondrial ATP synthesis by nitric oxide synthase activation triggered apoptosis in primary cortical neurons. J Neurochem 77:676-690

90. Patrick GN, Zukerberg L, Nikolic M, de la Monte S, Dikkes P, Tsai LH (1999) Conversion of $\mathrm{p} 35$ to $\mathrm{p} 25$ deregulates Cdk5 activity and promotes neurodegeneration. Nature 402:615-622

91. Li BS, Sun MK, Zhang L, Takahashi S, Ma W, Vinade L, Kulkarni AB, Brady RO, Pant HC (2001) Regulation of NMDA receptors by cyclin-dependent kinase-5. Proc Natl Acad Sci U S A 98:12742-12747

92. Konishi Y, Lehtinen M, Donovan N, Bonni A (2002) Cdc2 phosphorylation of BAD links the cell cycle to the cell death machinery. Mol Cell 9:1005-1016

93. Wen Y, Yang S, Liu R, Brun-Zinkernagels AM, Koulen P, Simpkins JW (2004) Transient cerebral ischemia induces aberrant neuronal cell cycle re-rentry and Alzheimer's disease-like tauopathy in female rats. J Biol Chem 279:22684-22692

94. Bolaños JP, Heales SJR, Land JM, Clark JB (1995) Effect of peroxynitrite on the mitochondrial respiratory chain: differential susceptibility of neurones and astrocytes in primary cultures. J Neurochem 64:1965-1972

95. Almeida A, Moncada S, Bolaños JP (2004) Nitric oxide switches on glycolysis through the AMP protein kinase and 6phosphofructo-2-kinase pathway. Nat Cell Biol 6:45-51

96. Wamelink MM, Struys EA, Jakobs C (2008) The biochemistry, metabolism and inherited defects of the pentose phosphate pathway: a review. J Inherit Metab Dis 31:703-717

97. Herrero-Mendez A, Almeida A, Fernandez E, Maestre C, Moncada S, Bolanos JP (2009) The bioenergetic and antioxidant status of neurons is controlled by continuous degradation of a key glycolytic enzyme by APC/C-Cdh1. Nat Cell Biol 11:747-752 